\title{
Atomic and molecular hydrogen budget in Titan's atmosphere
}

\author{
Sébastien Lebonnois, ${ }^{\mathrm{a}, *}$ E.L.O. Bakes, ${ }^{\mathrm{b}}$ and Christopher P. McKay ${ }^{\mathrm{b}}$ \\ ${ }^{a}$ Laboratoire Météorologie Dynamique, UPMC Jussieu, Box 99, 75252 Paris Cedex 05, France \\ ${ }^{\mathrm{b}}$ NASA Ames Research Center, MS 245-3, Moffett Field, CA 94035-1000, USA
}

Received 21 March 2002; revised 8 July 2002

\begin{abstract}
Using a one-dimensional model, we investigate the hydrogen budget and escape to space in Titan's atmosphere. Our goal is to study in detail the distributions and fluxes of atomic and molecular hydrogen in the model, while identifying sources of qualitative and quantitative uncertainties. Our study confirms that the escape of atomic and molecular hydrogen to space is limited by the diffusion through the homopause level. The $\mathrm{H}$ distribution and flux inside the atmosphere are very sensitive to the eddy diffusion coefficient used above altitude $600 \mathrm{~km}$. We chose a high value of this coefficient $1 \times 10^{8} \mathrm{~cm}^{2} \mathrm{~s}^{-1}$ and a homopause level around altitude $900 \mathrm{~km}$. We find that $\mathrm{H}$ flows down significantly from the production region above $500 \mathrm{~km}$ to the region [300-500] km, where it recombines into $\mathrm{H}_{2}$. Production of both $\mathrm{H}$ and $\mathrm{H}_{2}$ also occurs in the stratosphere, mostly from photodissociation of acetylene. The only available observational data to be compared are the escape rate of $\mathrm{H}$ deduced from Pioneer 11 and IUE observations of the $\mathrm{H}$ torus $1-3 \times 10^{9} \mathrm{~cm}^{-2} \mathrm{~s}^{-1}$ and the latest retrieved value of the $\mathrm{H}_{2}$ mole fraction in the stratosphere: $(1.1 \pm 0.1) \times 10^{-3}$. Our results for both of these values are at least $50-100 \%$ higher, though the uncertainties within the chemical schemes and other aspects of the model are large. The chemical conversion from $\mathrm{H}_{2} \mathrm{H}_{2}$ is essentially done through catalytic cycles using acetylene and diacetylene. We have studied the role of this diacetylene cycle, for which the associated reaction rates are poorly known. We find that it mostly affects $\mathrm{C}_{4}$ species and benzene in the lower atmosphere, rather than the $\mathrm{H}$ profile and the hydrogen budget. We have introduced the heterogenous recombination of hydrogen on the surface of aerosol particles in the stratosphere, and this appears to be a significant process, comparable to the chemical processes. It has a major influence on the $\mathrm{H}$ distribution, and consequently on several other species, especially $\mathrm{C}_{3} \mathrm{H}_{4}, \mathrm{C}_{4} \mathrm{H}_{2}$ and $\mathrm{C}_{6} \mathrm{H}_{6}$. Therefore, this heterogenous process should be taken into account when trying to understand the stratospheric distribution of these hydrocarbons.
\end{abstract}

(C) 2003 Elsevier Science (USA). All rights reserved.

Keywords: Titan; Photochemistry; Atmospheres, Composition

\section{Introduction}

The concentration and flux of $\mathrm{H}$ and $\mathrm{H}_{2}$ on Titan are critical to understanding the photochemistry of that satellite. Because of Titan's low gravity, hydrogen is irreversibly lost to space, preventing the buildup of a $\mathrm{H}_{2}$-rich atmosphere. The photochemistry that results is considerably different from that in the $\mathrm{H}_{2}$-rich atmosphere of the giant planets. In particular, the low concentration of $\mathrm{H}$ implies that the organic products of $\mathrm{CH}_{4}$ photochemistry are not recycled back to $\mathrm{CH}_{4}$, and unsaturated organics and even solid organic materials are stable in Titan's atmosphere. The key components of the hydrogen cycle on Titan are the photochemical

\footnotetext{
* Corresponding author. Fax: +33-144-27-6272.

E-mail address: sllmd@1md.jussieu.fr (S. Lebonnois).
}

production of $\mathrm{H}$, its conversion to the relatively inert $\mathrm{H}_{2}$, and the escape of both $\mathrm{H}$ and $\mathrm{H}_{2}$ from the top of the atmosphere.

The escape of atomic hydrogen was estimated from Pioneer 11 and IUE observations of the hydrogen torus, before the Voyager 1 data were available (Smyth, 1981), but no recent study has been performed to improve this first estimate. The most recent analysis of IRIS/Voyager 1 data indicates a mole fraction for $\mathrm{H}_{2}$ in the troposphere around 1 $\times 10^{-3}$ (Courtin et al., 1995; Samuelson et al., 1997).

Theoretical work on the distribution of $\mathrm{H}_{2}$ in the upper atmosphere (Hunten, 1973; Bertaux and Kockarts, 1983) shows that the escape to space of molecular hydrogen is limited by the diffusion around the homopause level (around altitude 900-1000 km). Yung et al. (1984) developed a photochemical model of Titan's atmosphere and 
pointed out the difficulties encountered in maintaining high densities of unsaturated hydrocarbons (which have been observed by Voyager 1) if atomic hydrogen was not efficiently converted into molecular hydrogen. They suggested a catalytic cycle involving diacetylene, which has been included in all the following photochemical models, though the rates used for these reactions are still uncertain at the present time. Toublanc et al. (1995) discussed briefly the role of this additional catalytic cycle in their photochemical model. They concluded that it has almost no influence on the stratospheric abundance of $\mathrm{C}_{2} \mathrm{H}_{\mathrm{x}}$ species. This apparent discrepancy has never been completely understood, although the differences between the two models are large enough to make a simple explanation unlikely. In their photochemical model, Lara et al. (1996) give some information about the fate of hydrogen in the atmosphere, but do not discuss in detail the hydrogen budget, nor do they discuss the role of the diacetylene catalytic cycle, which they take into account in their model.

In this paper, we used a one-dimensional photochemical model to study the equilibrium of $\mathrm{H}$ and $\mathrm{H}_{2}$ in the atmosphere of Titan. Our goal is to investigate in detail the distributions and fluxes of atomic and molecular hydrogen in the model, while identifying sources of qualitative and quantitative uncertainties. In Section 2, we detail the atmospheric fluxes of atomic and molecular hydrogen from their photochemical production to their escape to space at the top of the atmosphere. As previously indicated, the conversion of atomic to molecular hydrogen is a key process in this overall equilibrium. The chemistry of this process seems to be mainly controlled by two catalytic cycles, and this will be discussed in Section 3. A question that remained unexplored until now is the impact of possible heterogenous chemical processes, which would take place at the surface of the aerosol particles that are present in Titan's stratosphere. This recombination of $\mathrm{H}$ at the surface of aerosols has been recently studied (Bakes et al., 2003), and we have introduced this mechanism in our photochemical model to evaluate its possible impact on the chemical equilibrium of the atmosphere. The results of this study are developed in Section 4.

\section{Hydrogen equilibrium}

The hydrogen equilibrium in Titan's atmosphere is controlled on one hand by the production of atomic and molecular hydrogen from photodissociation and chemical reactions of atmospheric compounds, and on the other hand by their escape to space. We discuss here the equilibrium of $\mathrm{H}$ and $\mathrm{H}_{2}$ distributions in the context of a one-dimensional photochemical model, which takes into account the spherical geometry of the atmosphere.

\subsection{Photochemical model}

To study the hydrogen equilibrium, we used a 1-dimensional photochemical model, updated from Toublanc et al. (1995) (Lebonnois and Toublanc, 1999; Lebonnois et al., 2001). In this model, which we also used for our recent study of the photochemical production of aerosols in Titan's atmosphere (Lebonnois et al., 2002), the number of hydrocarbon and nitrile species and the number of photochemical reactions have been enhanced, especially to improve the nitrile schemes and to introduce benzene. Oxygen species are not included. The mole fractions of all chemical species included in the model are calculated throughout the atmosphere by solving the set of continuity equations, except for $\mathrm{N}_{2}$ (background gas). No constraints are added to these equations, except for boundary conditions (source flux of methane at the surface, source flux of $\mathrm{N}$ atoms, and escape flux of $\mathrm{H}$ and $\mathrm{H}_{2}$ at the top of the model) and condensation. The solar spectrum used to compute the photodissociation rates is taken from Huebner et al. (1992), for mean solar activity. In the following, the altitude scale $z$ is related to the radial distance scale $r$ with a radius of Titan $\mathrm{R}_{\mathrm{T}}$ $=2575 \mathrm{~km}, r=\mathrm{R}_{\mathrm{T}}+z$.

The boundary conditions for $\mathrm{H}$ and $\mathrm{H}_{2}$ escape at the top of the model have been evaluated as follows. The exobase (or critical level) is taken at $r_{c}=4100 \mathrm{~km}$, with a constant temperature $T_{c}=186 \mathrm{~K}$ between $r_{c}$ and the top of the model, $r_{\text {top }}=3875 \mathrm{~km}$ (Smith et al., 1982; Bertaux and Kockarts, 1983). The Jeans escape velocities are calculated at the exobase: $w_{\mathrm{H}, \mathrm{c}}=2.9 \times 10^{4} \mathrm{~cm} \mathrm{~s}^{-1} ; w_{\mathrm{H}_{2} \mathrm{c}}=7.9 \times 10^{3} \mathrm{~cm} \mathrm{~s}^{-1}$. Then, using the equation of diffusion in a spherical geometry as described in Bertaux and Kockarts (1983) and conservation of the $\mathrm{H}$ and $\mathrm{H}_{2}$ fluxes between $r_{\text {top }}$ and $r_{c}$, the escape velocities at the top boundary of our model are computed: $w_{\mathrm{H}, \text { top }}=$ $1.1 \times 10^{4} \mathrm{~cm} \mathrm{~s}^{-1} ; w_{\mathrm{H} 2 \text {,top }}=3.7 \times 10^{3} \mathrm{~cm} \mathrm{~s}^{-1}$.

At the bottom of the atmosphere, hydrogen is removed via the condensation of hydrocarbons and nitriles, as well as via the formation of heavy species (which have been labeled "soot" in photochemical models). The fate of these species is not tracked in the model but ultimately, they will either condense out of the atmosphere, or be incorporated in the material that forms the haze. In either case, they represent an irreversible loss of hydrogen to the surface.

In the stratosphere, the eddy diffusion coefficient $K_{\mathrm{v}}$ has been tuned to reproduce the effect of 2-dimensional dynamics on vertical profiles of chemical compounds. In the upper atmosphere, the location of the homopause and the value of the eddy diffusion coefficient there are still being discussed. The constraints come from the analysis of the UVS data on board Voyager 1. Smith et al. (1982) analyzed these data to retrieve the composition and structure of the upper atmosphere, and proposed a homopause level around $925 \mathrm{~km}$ altitude, with a value of the eddy diffusion coefficient, $K_{\mathrm{v}}$, around $1 \times 10^{8} \mathrm{~cm}^{2} \mathrm{~s}^{-1}$. According to their analysis, the methane mole fraction around $1140 \mathrm{~km}$ would be in the range 5-8\%, and the acetylene mole fraction around 840 $\mathrm{km}$ altitude would be 1-2\%. Strobel et al. (1992) proposed 


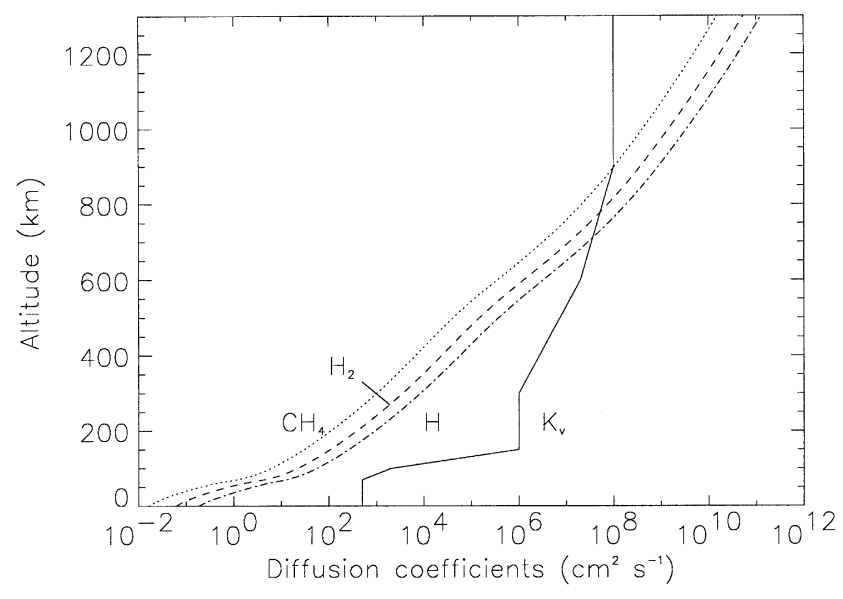

Fig. 1. Profiles used in our model for the eddy diffusion coefficient $\mathrm{K}_{v}$ (solid line) and for the molecular diffusion coefficients of $\mathrm{CH}_{4}$ (dotted line), $\mathrm{H}_{2}$ (dashed line), and $\mathrm{H}$ (dashed-dotted line).

another analysis, combining solar occultation and airglow data. They recommend a homopause level around $1000 \mathrm{~km}$, with $K_{v} \sim 4-8 \times 10^{8} \mathrm{~cm}^{2} \mathrm{~s}^{-1}$. In his recent P.h.D. work, Vervack conducted a reanalysis of the UVS data, with a new model of the detector and new techniques (Vervack, 1997; Vervack et al., 1999). His results concerning the homopause level are in agreement with those of Strobel et al. (1992), with a homopause located above altitude $1000 \mathrm{~km}$. Concerning the composition of the upper atmosphere, this work includes more UV absorbers in the analysis than that of Smith et al. (1982). As a result, the acetylene mole fraction retrieved is lowered and could be as low as around $10^{-4}$ in the region $800-1000 \mathrm{~km}$. Since the photochemical model is very sensitive to the $K_{\mathrm{v}}$ coefficient profile in the upper atmosphere, we had to make a choice (see Fig. 1). In the UVS discussion described above, the approximate level of the homopause is between altitudes 900 and $1100 \mathrm{~km}$ for all the analyses. We adopted the value of Smith et al. (1982) for the eddy diffusion coefficient, $K_{\mathrm{v}}=1 \times 10^{8} \mathrm{~cm}^{2} \mathrm{~s}^{-1}$ for altitudes above $900 \mathrm{~km}$. The methane mole fraction profile that results is in agreement with the constraint from Smith et al. (1982). The acetylene mole fraction profile is much lower than the 1-2\% level, but within the range of possibilities discussed by Vervack and co-workers (see Fig. 2). In previous photochemical models (such as Toublanc et al., 1995; Lara et al., 1996; or Lebonnois et al., 2001), $K_{\mathrm{v}}$ was lower by one order of magnitude to get a higher acetylene mole fraction above $800 \mathrm{~km}$. More data from observations are needed to better constrain the models, and the CassiniHuygens mission will be able to provide a more complete observational data set. The profile of the eddy diffusion coefficient chosen is plotted in Fig. 1, together with the molecular diffusion coefficients for $\mathrm{H}, \mathrm{H}_{2}$, and $\mathrm{CH}_{4}$.

Our model does not include any ions or ion-neutral reactions. The ionosphere of Titan was recently discussed in Galand et al. (1999) and Banaszkiewicz et al. (2000). Both studies coupled the ionospheric photochemistry with neutral photochemical models (respectively Toublanc et al., 1995, and Lara et al., 1996). Banaszkiewicz et al. (2000) compare the distributions of neutral species when the ionospheric scheme is introduced with the pure neutral case. It appears from their study that including ions can slightly modify the mole fractions of neutral species (by a factor less than or around 2 in the case of acetylene and atomic and molecular hydrogen). We neglect this effect in this paper. This may affect the production rates of $\mathrm{H}$ and $\mathrm{H}_{2}$ in the upper atmosphere, but does not affect our results in a major way.

The loss of gas compounds into aerosol production (e.g., Lebonnois et al., 2002) has not been included in these initial simulations. However, we have done some calculations that include this process in order to test the sensitivity of our conclusions (see Section 2.3).

In this model, the vertical profiles of the mole fractions of methane, acetylene, and ethylene are the most important for the photochemical production of atomic and molecular hydrogen. These profiles and the profiles of the mole fractions of $\mathrm{H}$ and $\mathrm{H}_{2}$ are plotted in Fig. 2 .

\subsection{Hydrogen fluxes}

Reaching complete equilibrium for the atomic hydrogen flux is easy. It is much more difficult for $\mathrm{H}_{2}$, because the time needed for the lowest atmospheric levels to attain equilibrium is excessively long (our simulations were done over a hundred Titan years). In Fig. 3, actual fluxes in the model are compared to the integration of photochemical production and loss, which indicates if the overall equilibrium is reached or not. The actual upward flux for $\mathrm{H}_{2}$ is too low by about $2 \times 10^{8} \mathrm{~cm}^{-2} \mathrm{~s}^{-1}$ throughout the atmosphere, which represents a few percent $(\sim 2.5 \%)$ of the total escape flux at the top of the atmosphere. The reason is a small downward flux in the lowest $180 \mathrm{~km}$, which slowly fills the troposphere. We consider that the equilibrium reached here is good enough for the purpose of this paper.

The loss terms for hydrogen include escape to space, condensation on the surface in species that are explicitly tracked in the model $\left(\mathrm{C}_{2} \mathrm{H}_{2}, \mathrm{C}_{2} \mathrm{H}_{6}, \mathrm{HCN}\right.$, etc. $)$, and loss to larger organic molecules and haze that are not explicitly tracked in the model. In Table 1 these latter two terms are labeled as other products and together represent a loss of 4.5 $\times 10^{9} \mathrm{~cm}^{-2} \mathrm{~s}^{-1}$. Microphysical models and tholin elemental ratios suggest that the sink of hydrogen due to the haze alone is $\simeq 4 \times 10^{8} \mathrm{~cm}^{-2} \mathrm{~s}^{-1}$ (McKay, 1996). Table 1 shows that the hydrogen budget is in balance; the difference between the total loss of $\mathrm{H}$ and the total production due to methane destruction is less than $1 \%$. For comparison, we also indicate in Table 1 the hydrogen fluxes obtained by previous photochemical models: Toublanc et al. (1995), from their Table 2 and Lara et al. (1996), from their Table 5 and text (p. 23,275), adjusted to the surface. There is a good general agreement between this work and those previous photochemical models.

The escape to space of molecular hydrogen has been 

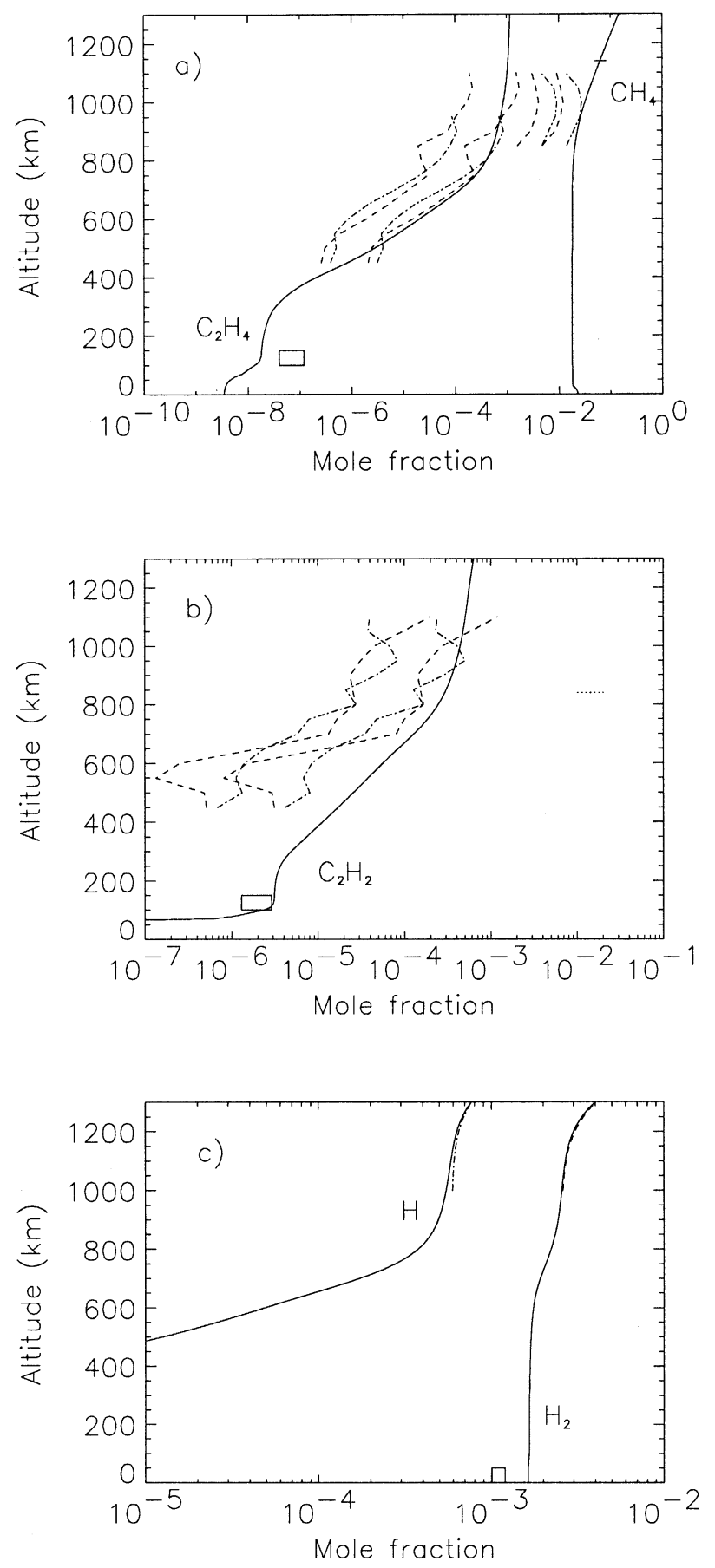

Fig. 2. Vertical profiles of (a) $\mathrm{CH}_{4}$ and $\mathrm{C}_{2} \mathrm{H}_{4}$, (b) $\mathrm{C}_{2} \mathrm{H}_{2}$, and (c) $\mathrm{H}$ and $\mathrm{H}_{2}$. The boxes in (a) and (b) are the observational constraints from IRIS/ Voyager 1, as retrieved by Coustenis et al. (1989). The constraints on methane (horizontal solid line) and acetylene (horizontal dotted line) in the upper atmosphere are from the Smith et al. (1982) analysis of UVS/ Voyager 1 data. The uncertainty regions between dashed-dotted (ingress) and dashed (egress) lines are taken from the Vervack (1997) reanalysis of UVS/Voyager 1 data. The box in (c) is the $\mathrm{H}_{2}$ mole fraction retrieved by Samuelson et al. (1997) in the troposphere. The dashed lines in (c) are analytical solutions of the diffusion equation (see text).

shown to be nearly equal to the diffusion-limiting flux at the homopause level (Hunten, 1973; Bertaux and Kockarts, 1983). Using the analytical model described in Bertaux and
Kockarts (1983), we estimate the profiles of the $\mathrm{H}$ and $\mathrm{H}_{2}$ mole fractions in the thermosphere (altitude $1000-1300 \mathrm{~km}$, taken as isothermal, $T=175 \mathrm{~K}$ ), where photochemical production and loss are neglected. Given the upward fluxes (taken from the photochemical model) and the escape velocities at the top of the atmosphere, the $\mathrm{H}$ and $\mathrm{H}_{2}$ mole fraction profiles resulting from diffusion are calculated in this region. As seen in Fig. 2, they are very near the actual profiles. The difference is due to the photochemical production in this region, which is neglected in the analytical calculation.

The actual homopause level for $\mathrm{H}$ and $\mathrm{H}_{2}$ is located between 700 and $800 \mathrm{~km}$ in our model. But photochemical production for both hydrogen species is significant below $1000 \mathrm{~km}$. We calculate the maximum diffusion flux $\Phi_{10}$ at altitudes 800 and $1000 \mathrm{~km}$ using Eq. 13 of Bertaux and Kockarts (1983),

$$
\Phi_{10}=\frac{D_{10}}{H_{0}}\left(1-\frac{m_{1}}{m}\right) n_{10}=D_{10}\left(\frac{1}{H_{0}}-\frac{1}{H_{10}}\right) n_{10},
$$

where the subscript 0 refers to the reference level $r_{0}(3375$, then $3575 \mathrm{~km}$ ), the subscript 1 refers to the minor compound ( $\mathrm{H}$ or $\left.\mathrm{H}_{2}\right), D$ is the molecular diffusion coefficient for this compound in $\mathrm{N}_{2}, m$ is the mean molecular mass, $n$ is the number density, and $H$ is the scale height. In Table 2, we compare this flux to the actual flux in the photochemical model for both atomic and molecular hydrogen. At $1000 \mathrm{~km}$ altitude, it is around $8 \%$ higher than the model flux for $\mathrm{H}$, and only $5 \%$ higher for $\mathrm{H}_{2}$. This confirms that both atomic and molecular hydrogen fluxes are limited by diffusion at altitude $800-1000 \mathrm{~km}$ of Titan's atmosphere, which acts as a bottleneck. The atomic hydrogen flux plotted in Fig. 3

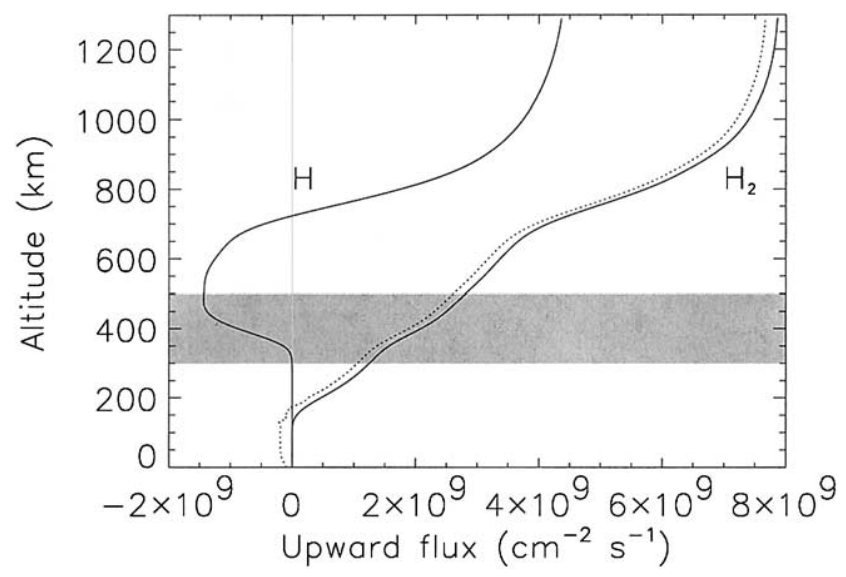

Fig. 3. Upward fluxes of atomic and molecular hydrogen, referred to the surface. Dotted lines are the fluxes obtained in the model; solid lines are the profiles of the integrated net production (or loss for negative values) of both species between the surface and a given altitude. Equilibrium is reached for $\mathrm{H}$, but a residual downward flux of $\mathrm{H}_{2}$ is still present in the lower levels of the atmosphere, which slowly fills the troposphere. This residual flux reduces by $2 \times 10^{8} \mathrm{~cm}^{-2} \mathrm{~s}^{-1}$ the upward flux above $200 \mathrm{~km}$ altitude. The dark region indicates the conversion of $\mathrm{H}$ flowing down from above into $\mathrm{H}_{2}$ (region II; see text). 
Table 1

Hydrogen budget: fluxes for production and removal in the atmosphere

\begin{tabular}{lllll}
\hline & T95 & L96 & Reference simulation & Haze growth scheme on $^{\mathrm{a}, \mathrm{b}}$ \\
\hline Destruction of $\mathrm{CH}_{4}$ & $5.2 \times 10^{10}$ & $3.3 \times 10^{10}$ & $3.7 \times 10^{10}$ & $3.4 \times 10^{10}$ \\
Escape to space & $2.6 \times 10^{10}$ & $1.3 \times 10^{10}$ & $2.0 \times 10^{10}$ & $2.0 \times 10^{10}$ \\
$\mathrm{H}$ & $6.5 \times 10^{8}$ & $2.5 \times 10^{9}$ & $4.4 \times 10^{9}$ & $4.4 \times 10^{9}$ \\
$\mathrm{H}_{2}$ & $2.0 \times 10^{10}$ & $1.1 \times 10^{10}$ & $1.5 \times 10^{10}$ & $1.5 \times 10^{10}$ \\
Condensates & $2.0 \times 10^{10}$ & $1.8 \times 10^{10}$ & $1.3 \times 10^{10}$ & $9.3 \times 10^{9}$ \\
$\mathrm{C}_{2} \mathrm{H}_{6}$ & $1.6 \times 10^{10}$ & $1.6 \times 10^{10}$ & $9.7 \times 10^{9}$ & $7.5 \times 10^{9}$ \\
$\mathrm{C}_{2} \mathrm{H}_{2}$ & $3.8 \times 10^{9}$ & $1.9 \times 10^{9}$ & $1.8 \times 10^{9}$ & $1.2 \times 10^{9}$ \\
$\mathrm{C}_{3} \mathrm{H}_{8}$ & $5.1 \times 10^{8}$ & $2.7 \times 10^{8}$ & $5.2 \times 10^{8}$ & $3.5 \times 10^{8}$ \\
$\mathrm{CH}_{3} \mathrm{CN}$ & & $2.0 \times 10^{6}$ & $2.2 \times 10^{8}$ & $4.6 \times 10^{7}$ \\
$\mathrm{HCN}^{\mathrm{HC}} \mathrm{N}$ & $5.6 \times 10^{7}$ & $9.4 \times 10^{7}$ & $1.8 \times 10^{8}$ & $5.1 \times 10^{7}$ \\
$\mathrm{C}_{4} \mathrm{H}_{2}$ & & $3.8 \times 10^{7}$ & $1.5 \times 10^{8}$ & $2.0 \times 10^{7}$ \\
Others & & $5.8 \times 10^{6}$ & $5.5 \times 10^{7}$ & $5.0 \times 10^{6}$ \\
Other products (total) & & $1.5 \times 10^{6}$ & $1.0 \times 10^{8}$ & $1.3 \times 10^{9}$ \\
Aerosols & & $3.2 \times 10^{9 \mathrm{~d}}$ & $4.5 \times 10^{9}$ & $4.3 \times 10^{9}$ \\
\end{tabular}

${ }^{\text {a }}$ Fluxes in $\mathrm{cm}^{-2} \mathrm{~s}^{-1}$, referred to the surface.

${ }^{\mathrm{b}}$ T95: Toublanc et al. (1995). Only available values are indicated. L96: Lara et al. (1996).

${ }^{\mathrm{c}}$ See text, and also Lebonnois et al. (2002).

${ }^{\mathrm{d}}$ All compounds produced and not destroyed in their Table 5.

${ }^{\mathrm{e}}$ Assumption based on microphysical models and elemental ratios obtained in laboratory experiments (McKay, 1996).

reveals an interesting point: $\mathrm{H}$ is flowing down between $\sim 700$ and $300 \mathrm{~km}$ altitude. This is due to a downward transport by eddy diffusion between the region of major production of $\mathrm{H}$ and a region where $\mathrm{H}$ is converted to $\mathrm{H}_{2}$ (see Fig. 4). We will point out the model-dependency of this result in Section 2.3.

The production and loss rates profiles for $\mathrm{H}$ and $\mathrm{H}_{2}$ are indicated in Fig. 4. Three regions can be detailed: a major production region for both $\mathrm{H}$ and $\mathrm{H}_{2}$ in the higher atmosphere (500-1000 km, region I); a region where most of the conversion from atomic to molecular hydrogen occurs (300-500 km, region II); and a production region for both $\mathrm{H}$ and $\mathrm{H}_{2}$ in the lower stratosphere $(100-300 \mathrm{~km}$, region III). The percentage of total production and loss that each region represents is indicated in Table 3.

In region I, both $\mathrm{H}$ and $\mathrm{H}_{2}$ are mainly produced through the photodissociation of $\mathrm{CH}_{4}$ and $\mathrm{C}_{2} \mathrm{H}_{4}$. Atomic hydrogen is also produced by the reaction

$$
\mathrm{CH}+\mathrm{CH}_{4} \rightarrow \mathrm{C}_{2} \mathrm{H}_{4}+\mathrm{H}
$$

and $\mathrm{H}_{2}$ by the reaction

Table 2

Comparison between the modeled fluxes of $\mathrm{H}$ and $\mathrm{H}_{2}$ and the diffusionlimiting fluxes, around the homopause and at the boundary layer

\begin{tabular}{llll}
\hline Altitude $(\mathrm{km})$ & 800 & 1000 & 1300 \\
\hline Atmospheric density $\left(\mathrm{cm}^{-3}\right)$ & $1.6 \times 10^{11}$ & $8.5 \times 10^{9}$ & $2.3 \times 10^{8}$ \\
$\mathrm{H}$ mole fraction & $3.7 \times 10^{-4}$ & $5.5 \times 10^{-4}$ & $7.6 \times 10^{-4}$ \\
Upward flux for $\mathrm{H}$ (model) & $1.7 \times 10^{9}$ & $3.7 \times 10^{9}$ & $4.4 \times 10^{9}$ \\
Diffusion-limited flux for $\mathrm{H}$ & $2.8 \times 10^{9}$ & $4.0 \times 10^{9}$ & $5.7 \times 10^{9}$ \\
$\mathrm{H}_{2}$ mole fraction & $2.2 \times 10^{-3}$ & $2.6 \times 10^{-3}$ & $4.0 \times 10^{-3}$ \\
Upward flux for $\mathrm{H}_{2}$ (model) & $5.5 \times 10^{9}$ & $7.2 \times 10^{9}$ & $7.7 \times 10^{9}$ \\
Diffusion-limited flux for $\mathrm{H}_{2}$ & $6.6 \times 10^{9}$ & $7.6 \times 10^{9}$ & $1.2 \times 10^{10}$
\end{tabular}

Fluxes in $\mathrm{cm}^{-2} \mathrm{~s}^{-1}$, referred to the surface.

$$
\mathrm{H}+{ }^{3} \mathrm{CH}_{2} \rightarrow \mathrm{H}_{2}+\mathrm{CH},
$$

which is also the main loss for $\mathrm{H}\left({ }^{3} \mathrm{CH}_{2}\right.$ is the ground state for the $\mathrm{CH}_{2}$ radical; ${ }^{1} \mathrm{CH}_{2}$ is an excited state). Destruction of methane and production of $\mathrm{H}$ and $\mathrm{H}_{2}$ are closely linked in this region: $\mathrm{CH}_{4}$ photodissociation produces the radicals $\mathrm{CH},{ }^{1} \mathrm{CH}_{2}$, and $\mathrm{CH}_{3}$, with $\mathrm{H}$ and $\mathrm{H}_{2}$. $\mathrm{CH}_{3}$ is also photodissociated into ${ }^{1} \mathrm{CH}_{2}+\mathrm{H}$. ${ }^{1} \mathrm{CH}_{2}$ gives ${ }^{3} \mathrm{CH}_{2}$ through collisions; then reactions (R1) and (R2) conclude the scheme:

(Scheme I)

$$
\begin{aligned}
\mathrm{CH}_{4} & +\mathrm{CH}_{4} \rightarrow \mathrm{C}_{2} \mathrm{H}_{4} \\
& +\mathrm{H}_{2}+\left(\mathrm{H}_{2} \text { or } 2 \mathrm{H}\right) .
\end{aligned}
$$

The reaction (R2) is one of the chemical conversion pathways from atomic to molecular hydrogen in region II. The other pathways are the catalytic cycles using $\mathrm{C}_{2} \mathrm{H}_{2} / \mathrm{C}_{2} \mathrm{H}_{3}$ on one hand and $\mathrm{C}_{4} \mathrm{H}_{2} / \mathrm{C}_{4} \mathrm{H}_{3}$ on the other hand. The acetylene catalytic cycle appears to be dominant in this model, as will be discussed in Section 3. The photolytic production of hydrogen in this region comes from the photodissociation of $\mathrm{C}_{2} \mathrm{H}_{2}$ and $\mathrm{C}_{2} \mathrm{H}_{4}$. The net destruction of $\mathrm{H}$ atoms is $1.44 \times$ $10^{9} \mathrm{~cm}^{-2} \mathrm{~s}^{-1}$, and these atoms are converted into $9.6 \times 10^{8}$ $\mathrm{cm}^{-2} \mathrm{~s}^{-1} \mathrm{H}_{2}$ molecules. The net conversion is not in the ratio $2 \mathrm{H}: 1 \mathrm{H}_{2}$ because of reaction (R2). The catalytic destruction of methane is closely linked to hydrogen production in region II. Photodissociation of acetylene produces both hydrogen and radicals $\left(\mathrm{C}_{2}, \mathrm{C}_{2} \mathrm{H}\right)$ that will react with methane to form $\mathrm{CH}_{3}$. This radical mainly recombines to form ethane, concluding the catalytic scheme

$$
\text { (Scheme II) } \quad \begin{aligned}
\mathrm{CH}_{4} & +\mathrm{CH}_{4} \rightarrow \mathrm{C}_{2} \mathrm{H}_{6} \\
& +\left(\mathrm{H}_{2}, 2 \mathrm{H} \text { or } \mathrm{H}+\frac{1}{2} \mathrm{H}_{2}\right) .
\end{aligned}
$$

But $\mathrm{CH}_{3}$ will still be photodissociated by ultraviolet (216 

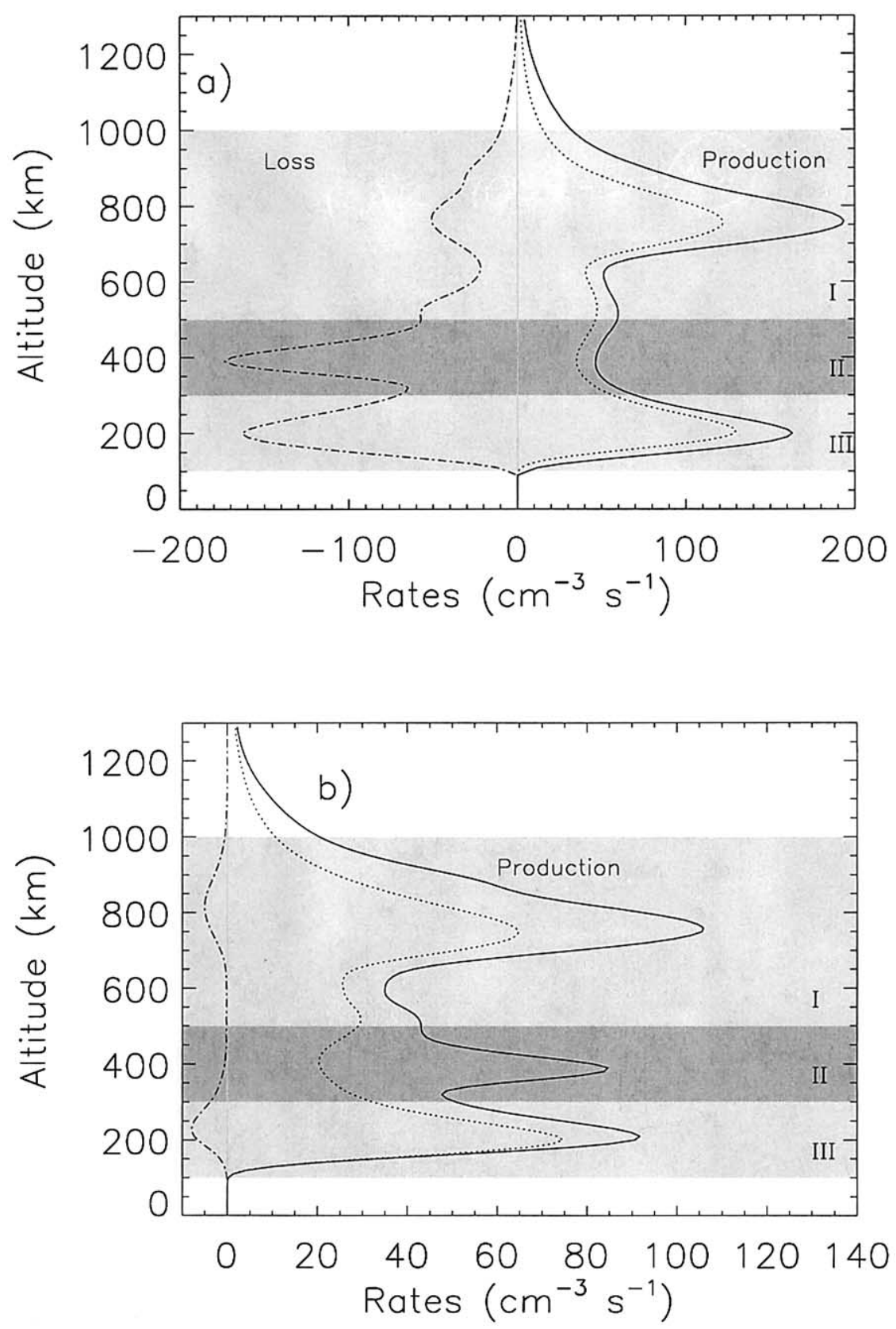

Fig. 4. Profiles of the total production rate (solid line) and loss rate (dashed-dotted line) for (a) $\mathrm{H}$ and (b) $\mathrm{H}_{2}$, when no heterogenous chemistry is present. Also plotted is the profile of the production rate only due to photodissociation processes (dotted line). The three main regions discussed in the text are shown in shades.

$\mathrm{nm}$, Arthur, 1986), and this will result in approximately the same methane destruction scheme as in region I (Scheme I).

In region III, atomic hydrogen is in photochemical equilibrium. The production of both hydrogen species is essentially due to the photodissociation of acetylene. The global hydrogen production in this region is therefore very sensitive to the stratospheric mole fraction of $\mathrm{C}_{2} \mathrm{H}_{2}$.

The escape to space of atomic hydrogen has been deduced from Pioneer 11 and IUE observations of the $\mathrm{H}$ torus around Titan (Smyth, 1981). This escape flux is constrained to $1-3 \times 10^{9} \mathrm{~cm}^{-2} \mathrm{~s}^{-1}$ (referred to the surface), but this model may need an update to take into account Voyager observations. The escape flux of $\mathrm{H}$ atoms in our model is at least $50 \%$ higher than this constraint. The $\mathrm{H}_{2}$ content of the atmosphere seems to indicate the same trend, since the tropospheric level of $\mathrm{H}_{2}$ is $1.6 \times 10^{-3}$ in the model, when the latest retrieval indicates a tropospheric level of $(1.1 \pm$ $0.1) \times 10^{-3}$ (Samuelson et al., 1997). Among previous photochemical models, Lara et al. (1996) and Lebonnois et al. (2001) had better agreements with these observations. However, it must be noted that the uncertainties within the photochemical data are significant (see the discussion in 
Table 3

Distribution of production and loss fluxes of $\mathrm{H}$ and $\mathrm{H}_{2}$

\begin{tabular}{llll}
\hline Regions Altitudes $(\mathrm{km})$ & I $1000-500$ & II 500-300 & III 300-100 \\
\hline $\mathrm{H}$ production (\% of total H production) & $8.0 \times 10^{9}(63 \%)$ & $1.5 \times 10^{9}(12 \%)$ & $2.5 \times 10^{9}(20 \%)$ \\
$\mathrm{H}$ photolytic production (\% of total H production) & $5.1 \times 10^{9}(40 \%)$ & $1.2 \times 10^{9}(10 \%)$ & $1.8 \times 10^{9}(14 \%)$ \\
$\mathrm{H}$ loss (\% of total $\mathrm{H}$ loss) & $2.8 \times 10^{9}(34 \%)$ & $2.9 \times 10^{9}(35 \%)$ & $2.5 \times 10^{9}(30 \%)$ \\
$\mathrm{H}_{2}$ net production $\%$ of $\mathrm{H}_{2}$ escape flux) & $4.7 \times 10^{9}(61 \%)$ & $1.6 \times 10^{9}(21 \%)$ & $1.2 \times 10^{9}(16 \%)$ \\
$\mathrm{H}_{2}$ photolytic production (\% of $\mathrm{H}_{2}$ escape flux) & $2.9 \times 10^{9}(38 \%)$ & $6.8 \times 10^{8}(9 \%)$ & $1.1 \times 10^{9}(14 \%)$ \\
\hline
\end{tabular}

Production and loss rates integrated over the vertical region, in $\mathrm{cm}^{-2} \mathrm{~s}^{-1}$, referred to the surface.

Dobrijevic and Parisot, 1998) and that the constraints on the composition are few and also significantly uncertain. Together with all the sources of uncertainty that we will discuss in the next section, it is difficult to put confidence in a close agreement.

\subsection{Discussion}

Many details in the model are subject to uncertainty and can have a qualitative as well as a quantitative impact on the results presented here. These details are related to photochemistry, but also to dynamics in different regions of the atmosphere and interactions with the haze layer (production, ultraviolet transmission).

The choice of the eddy diffusion coefficient profile, $K_{\mathrm{v}}$, was detailed with the description of the model. This profile does have a strong impact on the hydrogen fluxes, especially on the downward flux of $\mathrm{H}$ from region I to region II. The values of $K_{\mathrm{v}}$ in the mesosphere control the ratio between the downward and the upward flux of $\mathrm{H}$ (this ratio is $1.44 \times 10^{9} / 4.37 \times 10^{9}$ $=0.33$ in Fig. 3). With a lower $K_{\mathrm{v}}$ coefficient above $600 \mathrm{~km}$, atomic hydrogen would be in photochemical equilibrium up to higher in the atmosphere, and the downward flow that we have described could be reduced, or even become negligible. The conversion from $\mathrm{H}$ to $\mathrm{H}_{2}$ would then be located directly in the production region, and there would be much less conversion in region II.

The photochemical scheme used for the photodissociation of methane also influences fluxes in region I. In our photochemical model, we used the second scheme from Mordaunt et al. (1993) for the photodissociation of methane (see, e.g., Lebonnois et al., 2001). We also tested the influence of this scheme on $\mathrm{H}$ and $\mathrm{H}_{2}$ production by using either the first scheme from Mordaunt et al. (1993), or the more recent scheme published by Smith and Raulin (1999). The main impact of these two schemes is to favor ${ }^{1} \mathrm{CH}_{2}$ over $\mathrm{CH}$ in the photodissociation of methane. This step directly produces $\mathrm{H}_{2}$, and $\mathrm{CH}_{2}$ also favors the recombination of $\mathrm{H}$ into $\mathrm{H}_{2}$ (reaction R2). Therefore, $\mathrm{H}_{2}$ production is increased and $\mathrm{H}$ production is decreased. The net hydrogen escape remains approximately the same, but balance between $\mathrm{H}$ and $\mathrm{H}_{2}$ is affected.

In region II, the main factors that influence both the catalytic destruction of $\mathrm{CH}_{4}$ and the hydrogen production are the absorption of ultraviolet by the haze layer (in the range $160-250 \mathrm{~nm}$ ), and the dynamics in this region that shape the acetylene and ethylene vertical profiles.

The introduction of the scheme used for aerosol growth in Lebonnois et al. (2002) also has an impact on the hydrogen budget. Since it adds a loss of gas phase molecules (e.g., $\mathrm{C}_{2} \mathrm{H}_{2}, \mathrm{HCN}$ ) to the haze, it slightly reduces the mole fraction of acetylene in the stratosphere. This reduces the hydrogen production in region III. Table 1 shows that it affects only slightly the global budget of hydrogen. The total flux of hydrogen into heavy products remains approximately the same, but a much larger fraction is incorporated into the haze. The hydrogen sink into the haze reaches $2.5 \times 10^{9}$ $\mathrm{cm}^{-2} \mathrm{~s}^{-1}$. This is around five to six times higher than the expected value from 1-dimensional microphysical models. However, the introduction of general circulation dynamics in 2-dimensional microphysical models modifies the global budget of haze in the stratosphere. In particular, it increases the loss of haze particles to the ground in regions of subsidence. Therefore, 2-dimensional microphysical models need a much higher (around one order of magnitude larger) source function for the aerosols than 1-dimensional microphysical models, which is more consistent with the value obtained with our model (Rannou et al., 2002).

To better constrain the model, a better knowledge of the thermospheric conditions and composition would help. Also, the interactions between the aerosol layer and the photochemistry need to be more completely understood. The conversion of $\mathrm{H}$ to $\mathrm{H}_{2}$ occurs exclusively through chemical reactions in the model we used here, as it was the case in previous photochemical models. But a remaining question is: are there other mechanisms that can make this conversion, and what would be their influence on stratospheric composition?

\section{Chemical conversion from atomic to molecular hydrogen}

One of the major works to model the photochemistry of Titan's atmosphere has been done by Yung et al. (1984). In this model, the authors argued that the chemical cycle

$$
\begin{aligned}
& \text { (R3) } \mathrm{H}+\mathrm{C}_{2} \mathrm{H}_{2}+\mathrm{M} \rightarrow \mathrm{C}_{2} \mathrm{H}_{3}+\mathrm{M} \\
& \mathrm{H}+\mathrm{C}_{2} \mathrm{H}_{3} \rightarrow \mathrm{H}_{2}+\mathrm{C}_{2} \mathrm{H}_{2} \\
& \hline
\end{aligned}
$$

Cycle $1 \quad \mathrm{H}+\mathrm{H} \rightarrow \mathrm{H} 2$


was not sufficient for the conversion of atomic to molecular hydrogen, and they introduced another cycle:

(R5) $\mathrm{H}+\mathrm{C}_{4} \mathrm{H}_{2}+\mathrm{M} \rightarrow \mathrm{C}_{4} \mathrm{H}_{3}+\mathrm{M}$

$$
\mathrm{H}+\mathrm{C}_{4} \mathrm{H}_{3} \rightarrow \mathrm{H}_{2}+\mathrm{C}_{4} \mathrm{H}_{2}
$$

or

$$
\mathrm{H}+\mathrm{C}_{4} \mathrm{H}_{3} \rightarrow \mathrm{C}_{4} \mathrm{H}_{4}
$$

(R8)

$$
\mathrm{C}_{4} \mathrm{H}_{4}+\mathrm{h} \nu \rightarrow \mathrm{H}_{2}+\mathrm{C}_{4} \mathrm{H}_{2}
$$

Cycle 2

$$
\mathrm{H}+\mathrm{H} \rightarrow \mathrm{H}_{2} \text {. }
$$

The reactions $(\mathrm{R} 7+\mathrm{R} 8)$ were not included in their model, but were contained in reaction (R6). The Lara et al. (1996) model was very similar to the Yung et al. (1984) model for this cycle.

In their model, Toublanc et al. (1995) reported that the composition of the atmosphere was not very sensitive to the presence or absence of this diacetylene catalytic cycle, but did not explain the reasons for this difference between their results and those of Yung et al. (1984). Indeed, it is not easy to understand why these models would behave differently. When the composition profiles and the chemical data are compared, it seems that in both models, the destruction rate of $\mathrm{H}$ through (R5) should dominate over the rate through (R3) above $300 \mathrm{~km}$. When reactions (R5) and (R6) are turned to zero in the Toublanc et al. (1995) model, the hydrogen profile must have adapted so that (R3) can destroy all the $\mathrm{H}$ produced. According to the authors, this has a small impact on the $\mathrm{C}_{2} \mathrm{H}_{\mathrm{x}}$ compounds, as well as on the escape of $\mathrm{H}$ and $\mathrm{H}_{2}$. They do not go into detail about other compounds.

In a recent 2-dimensional photochemical model, Lebonnois et al. (2001) demonstrated the importance of meridional dynamical transport on the distributions of chemical compounds. The vertical profiles of acetylene and diacetylene (among others) were significantly modified compared to previous 1-dimensional models. Under such conditions, around $400 \mathrm{~km}$ in altitude, the acetylene mole fraction is lowered by a factor around 3 , which reduces production of diacetylene. Cycle 2 becomes less efficient, and the $\mathrm{H}$ mole fraction increases by more than one order of magnitude in this region (compared to Yung et al., 1984), until Cycle 1 becomes dominant.

In order to better assess the role of Cycle 2 in our 1-dimensional model described in this paper, we ran a simulation without this cycle, i.e., not taking into account reactions (R5), (R6) and (R7). This simulation represents an extreme situation, since these reactions may have a rate intermediate between zero and the rates used in the reference simulation.

The effects of the removal of Cycle 2 are plotted in Fig. 5. Both $\mathrm{C}_{2} \mathrm{H}_{2}$ and $\mathrm{H}$ mole fraction profiles show a 30 to $40 \%$ increase below $400 \mathrm{~km}$ altitude. This is linked to the necessary increase of Cycle 1 to account for the previous effect of Cycle 2 in the conversion of atomic to molecular hydrogen. Such an increase in the acetylene profile induces an rather similar increase for the other $\mathrm{C}_{2}$ species mole frac-
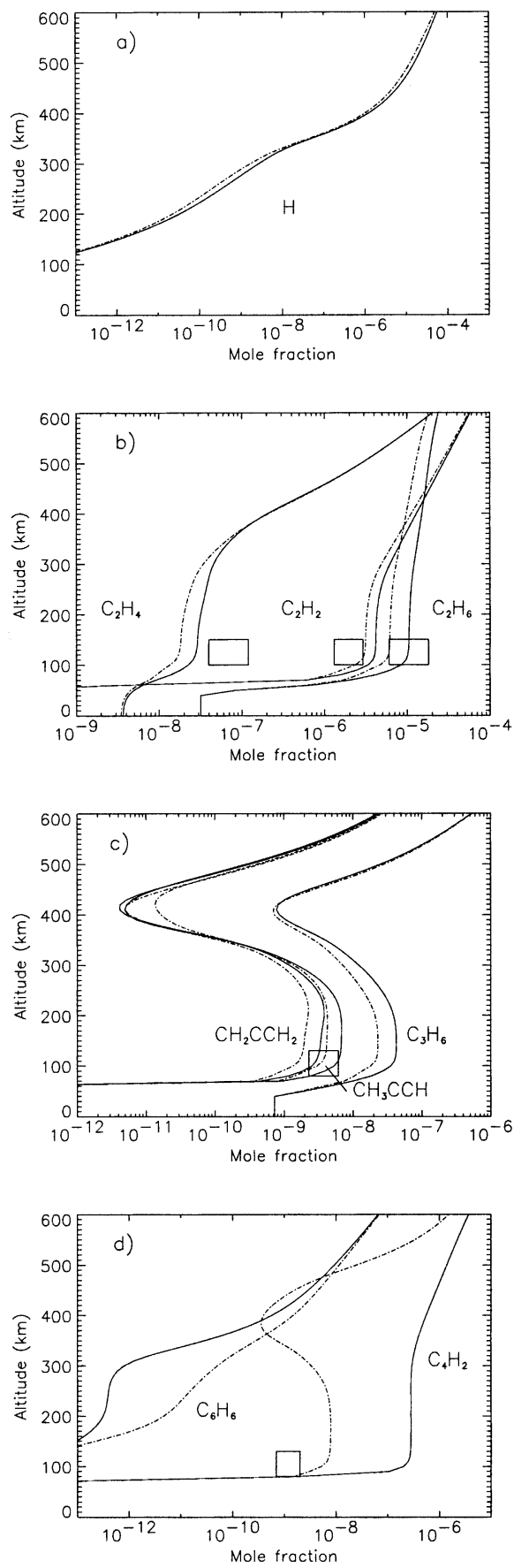

Fig. 5. Comparison of vertical profiles for several compounds: with (dashed-dotted line) and without (solid line) the catalytic cycle of $\mathrm{H}$ to $\mathrm{H}_{2}$ based on diacetylene. (a) Atomic hydrogen; (b) $\mathrm{C}_{2}$ species; (c) $\mathrm{C}_{3}$ species; (d) diacetylene and benzene.

tions, as well as for the $\mathrm{C}_{3}$ species. It also induces a slightly higher catalytic destruction rate of methane, which yields a $\sim 10 \%$ higher total $\mathrm{H}_{2}$ production rate. The major effect of Cycle 2 not being included is seen in Fig. 5d. The main loss of $\mathrm{C}_{4} \mathrm{H}_{2}$ has been removed, and this induces large modifications in the photochemical equilibrium of the $\mathrm{C}_{4}$ species: the $\mathrm{C}_{4} \mathrm{H}_{2}$ mole fraction increases by a factor of $\sim 30$ in the stratosphere (which deteriorates significantly the fit to the 
observations), $\mathrm{C}_{4} \mathrm{H}_{3}$ abundance is divided by 7 orders of magnitude in this region (no more significant chemical production), $\mathrm{C}_{4} \mathrm{H}_{4}$ and $\mathrm{C}_{4} \mathrm{H}_{5}$ abundances are reduced by approximately 2 orders of magnitude, and benzene is reduced by a factor of $\sim 50$. This is a significant problem concerning diacetylene, but the impact on the hydrogen budget is relatively limited, which is consistent with the conclusions of Toublanc et al. (1995).

A better measure of the rates of reactions (R5) to (R8) in Titan's atmospheric conditions would be very important to really conclude on the role of Cycle 2. The respective effect of Cycle 1 and Cycle 2 in region II appears also to be sensitive to the dynamics in this mostly unknown region of Titan's atmosphere, through the respective mixing of acetylene and diacetylene.

\section{Heterogenous processes}

\subsection{Description}

The presence of aerosols in the stratosphere of Titan can significantly modify the problem of $\mathrm{H}$-to- $\mathrm{H}_{2}$ conversion. Yung et al. (1984) suggested that the recombination of $\mathrm{H}$ on the surface of aerosol particles would serve the same purpose as the gas phase chemical cycle they introduced (Cycle 2). Heterogenous processes that can occur on the surfaces of aerosol particles, and therefore interfere with the purely chemical problem described previously, include hydrogenation of the chemical constituents of the aerosols, simple adsorption of hydrogen atoms, and reaction of a hydrogen atom on the surface with production of molecular hydrogen. The efficiency of the latter processus has been investigated in a recent work (Bakes et al., 2003).

In order to compare the efficency of such processes to the chemical cycles, we have introduced them into the photochemical model. We used the Prompt Reaction Model described in Bakes et al. (2003) to estimate the production rate of molecular hydrogen. In this model, one gas phase hydrogen atom collides with the surface of an aerosol particle and reacts with a second hydrogen atom which is already adsorbed (or chemically bounded) on the surface, to produce one molecule of $\mathrm{H}_{2}$. In the gas phase, the production rate of molecular hydrogen and corresponding loss rate of atomic hydrogen are

$$
-\frac{d n_{\mathrm{H}}}{d t}=\frac{d n_{\mathrm{H}_{2}}}{d t}=n_{\mathrm{H}} \times v_{\mathrm{H}} \times n_{\text {haze }} \times N \times \sigma_{1}
$$

where $n_{\mathrm{H}}$ (resp. $n_{\mathrm{H} 2}$ and $n_{\text {haze }}$ ) is the number density of $\mathrm{H}$ atoms (resp. $\mathrm{H}_{2}$ molecules and aerosol particles) in the gas phase, $v_{\mathrm{H}}$ is the speed of collision between an hydrogen atom and a haze particle, $N$ is the number of possible reaction sites for $\mathrm{H}$ atoms on the surface of a haze particle, and $\sigma$ is the cross section for hydrogen abstraction $\left(\mathrm{cm}^{2}\right)$, which is given by the expression (Bakes et al., 2003)

$$
\begin{aligned}
\sigma= & \gamma \exp \left(-\frac{q}{k_{B} T}\right)=1.0 \\
& \times 10^{-15} \exp \left(-\frac{1700}{T}\right) .
\end{aligned}
$$

To estimate $v_{\mathrm{H}}$, we have been using the thermal kinetic speed of hydrogen atoms,

$$
v_{\mathrm{H}}=\sqrt{\frac{3 k_{\mathrm{B}} T}{m_{\mathrm{H}}}},
$$

which is on the order of $2 \mathrm{~km} \mathrm{~s}^{-1}$ for $T=170 \mathrm{~K}$, much larger than Titan's wind speeds (on the order of $10^{2} \mathrm{~m} \mathrm{~s}^{-1}$ for zonal winds in the stratosphere). $N$ is difficult to evaluate. It is related to the number of carbon atoms at the surface of the aerosol particle, and using a cross section for each carbon of $s_{\text {ref }} \simeq 2.5 \times 10^{-16} \mathrm{~cm}^{2}$, we have

$$
N=\frac{4 \pi r_{\text {haze }}^{2}}{S_{\text {ref }}}
$$

where $r_{\text {haze }}$ is the radius of the aerosol particle. For the aerosol distribution and properties, we used the model of Toon et al. (1992). In Fig. 17 of this paper, the authors indicate the mean radius of the particles (averaged over the surface areas), which is around $0.1 \mu \mathrm{m}$. We used this radius for $r_{\text {haze }}$, and therefore the total number density of particles for $n_{\text {haze }}$ obtained from their Fig. 15

To balance the hydrogen budget of the aerosols, we also included an adsorption rate of atomic hydrogen on the aerosols' surface. As a first approximation, this rate has been taken equal to the production rate of molecular hydrogen previously described, in order to balance atomic hydrogen loss and molecular hydrogen production in the gas phase. However, it is possible that hydrogenation of the macromolecules that are constituents of the aerosols occurs, and therefore constitutes a net sink for hydrogen atoms in the gas phase. In addition, internal chemical rearrangements could also lead to a net exchange of hydrogen atoms between the gas phase and the haze. This has been neglected for the moment, as it is difficult to estimate.

\subsection{Consequences}

Fig. 6 is the same as Fig. 4, but for a simulation including the heterogenous recombination of hydrogen presented above. The profiles of the loss rate of $\mathrm{H}$ and of the production rate of $\mathrm{H}_{2}$ due to this process are added. In this simulation, the heterogenous recombination of hydrogen becomes one of the dominant process, and replaces a large fraction of the chemical reactions destroying $\mathrm{H}$. The major consequence is the reduction of the $\mathrm{H}$ mole fraction profile in the region 200-500 km (Fig. 7a), which induces changes in the chemical equilibrium of several species. The mole fraction profiles of $\mathrm{C}_{2}$ and $\mathrm{C}_{3}$ species, as well as $\mathrm{C}_{4} \mathrm{H}_{2}$ and $\mathrm{C}_{6} \mathrm{H}_{6}$, are shown in Fig. 7. $\mathrm{C}_{2}$ species undergo moderate 


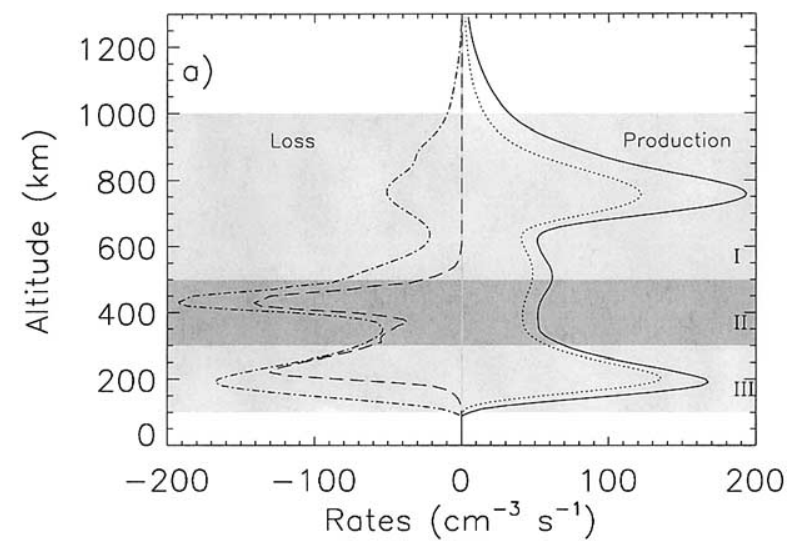

ग)

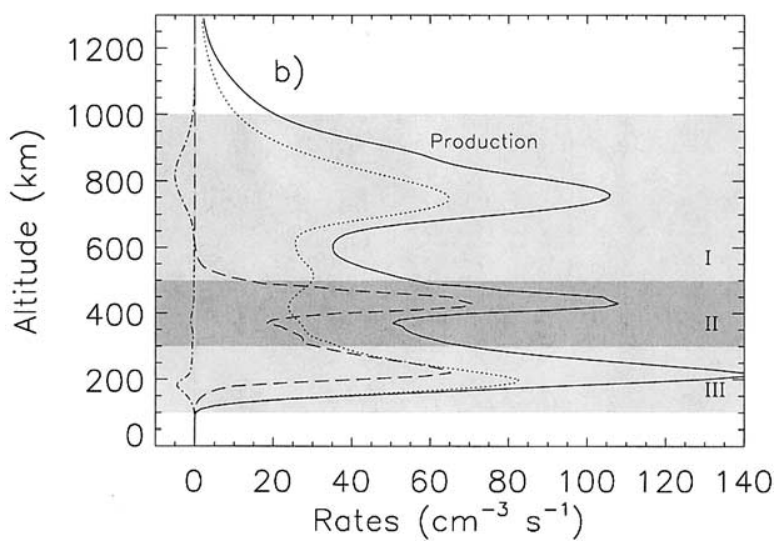

Fig. 6. Same as Fig. 4, but with the heterogenous chemistry added. The profiles of the production rate of $\mathrm{H}_{2}$ and loss rate of $\mathrm{H}$ are plotted in dashed lines.

changes. For $\mathrm{C}_{3}$ species, diacetylene, and benzene, the changes are much larger, since their chemistry is very dependent on $\mathrm{H}$. The nitriles do not seem to be significantly affected by the introduction of this process.

The $\mathrm{H}_{2}$ total production increases by approximately $10 \%$. As in Section 3, the increase in catalytic destruction of methane confirms that this is linked to the small increase in acetylene, which induces a small increase in the hydrogen production in the regions II and III. Another possible effect may be that the heterogenous conversion of $\mathrm{H}$ into $\mathrm{H}_{2}$ replaces several reactions that were destroying $\mathrm{H}$ without producing $\mathrm{H}_{2}$; for example,

$$
\begin{array}{lrl}
\text { (R9) } & \mathrm{C}_{2} \mathrm{H}_{4}+\mathrm{H}+\mathrm{M} \rightarrow \mathrm{C}_{2} \mathrm{H}_{5}+\mathrm{M} \\
\text { (R10) } & \mathrm{C}_{2} \mathrm{H}_{5}+\mathrm{H} & \rightarrow 2 \mathrm{CH}_{3} \\
\text { or } & & \\
\text { (R5) } & \mathrm{C}_{4} \mathrm{H}_{2}+\mathrm{H}+\mathrm{M} & \rightarrow \mathrm{C}_{4} \mathrm{H}_{3}+\mathrm{M} \\
\text { (R7) } & \mathrm{C}_{4} \mathrm{H}_{3}+\mathrm{H} & \rightarrow \mathrm{C}_{4} \mathrm{H}_{4} \\
\text { (R11) } & \mathrm{C}_{4} \mathrm{H}_{4}+\mathrm{H} & \rightarrow \mathrm{C}_{4} \mathrm{H}_{5} \\
\text { (R12) } & \mathrm{C}_{4} \mathrm{H}_{4}+\mathrm{h} \nu & \rightarrow 2 \mathrm{C}_{2} \mathrm{H}_{2} .
\end{array}
$$

These previous reactions (R5, R7, R11, and R12) may explain the increase of $\mathrm{C}_{4} \mathrm{H}_{2}$ associated with the decrease in
$\mathrm{H}$ abundance, and also the modifications of the distributions of $\mathrm{C}_{4} \mathrm{H}_{5}$ and $\mathrm{C}_{6} \mathrm{H}_{6}$ (benzene), since the reaction between $\mathrm{C}_{4} \mathrm{H}_{5}$ and acetylene is one of the main production pathways of benzene in this region $(200-350 \mathrm{~km})$.

The effects of the introduction of this heterogenous conversion are also compared with the role of Cycle 2, which is on in the study described above. In a last simulation, we kept the heterogenous recombination on, but removed Cycle
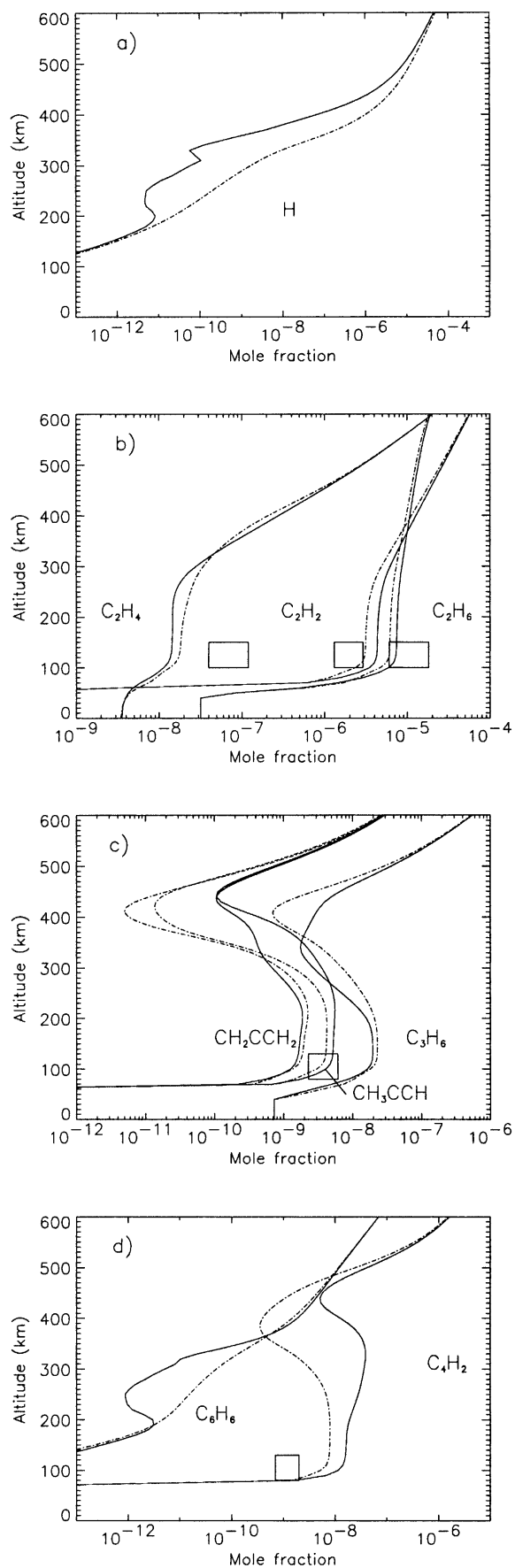

Fig. 7. Comparison of vertical profiles for several compounds: with (solid line) and without (dashed-dotted line) heterogenous recombination of $\mathrm{H}$ into $\mathrm{H}_{2}$. (a) Atomic hydrogen; (b) $\mathrm{C}_{2}$ species; (c) $\mathrm{C}_{3}$ species; (d) diacetylene and benzene. 
2, as was done in Section 3. Both effects cumulate. The same adjustments seen in Fig. 5 are obtained: slight enhancement of $\mathrm{H}$ and $\mathrm{C}_{2} \mathrm{H}_{2}$, with the subsequent enhancements of $\mathrm{C}_{2}$ and $\mathrm{C}_{3}$ species, profound modification of $\mathrm{C}_{4}$ species, and benzene. This is due to the fact that even with the significant modifications induced by the presence of the heterogenous reaction, profiles must adjust to replace Cycle 2. Therefore, if we compare only the simulations that do not include Cycle 2, the conclusions detailed previously concerning the impact of heterogenous recombination are similar. The only difference is for diacetylene. Its mole fraction does not vary when the heterogenous recombination is included, since without Cycle 2, its chemistry no longer depends on the $\mathrm{H}$ abundance.

\section{Conclusions}

We have used a one-dimensional photochemical model of Titan's atmosphere to investigate the hydrogen budget and to study the impact of the conversion from atomic to molecular hydrogen at the surface of aerosol particles on the composition of the atmosphere. A precise simulation of hydrogen fluxes in the upper atmosphere is difficult, due to the lack of confirmed data constraining the dynamics in the thermosphere. The value of the eddy diffusion coefficient above $600 \mathrm{~km}$ has a critical impact on the atomic hydrogen fluxes. Despite the uncertainties in the model, our study allows us to draw the following conclusions:

- We find, as others have before, that the escape of both atomic and molecular hydrogen to space is limited by diffusion through the homopause level.

- Atomic hydrogen may flow down significantly from the major production region (around altitude $800 \mathrm{~km}$ ) to the mesosphere, where its conversion to molecular hydrogen occurs.

- Destruction of methane and production of hydrogen are closely linked, through photodissociation of methane in the upper atmosphere, and through catalytic dissociation of methane in the mesosphere. In the upper atmosphere, the scheme used for the photodissociation of methane can affect the ratio between $\mathrm{H}$ and $\mathrm{H}_{2}$ production. In the mesosphere and stratosphere, the major parameters that affect hydrogen production are absorption of ultraviolet radiation by the haze layer and dynamical processes.

- Conversion from atomic to molecular hydrogen is a significant process in the overall equilibrium of hydrogen in the atmosphere. As far as homogenous photochemistry is concerned, this conversion is controlled mainly by two catalytic cycles, based on acetylene and diacetylene. The diacetylene cycle needs more accurate chemical data, but our model shows that this cycle has more significant impact on $\mathrm{C}_{4}$ species abundances in the lower atmosphere than on the hydrogen budget.
The respective role of each cycle is also dependent on dynamical processes in the atmosphere, which affect acetylene and diacetylene distributions.

- Heterogenous recombination of atomic to molecular hydrogen on the surfaces of aerosol particles has been evaluated, and it appears to be a significant process, dominant over chemical processes in the region 200$500 \mathrm{~km}$. Taking into account that this process decreases the $\mathrm{H}$ mole fraction, therefore affects the distribution of several hydrocarbons: it raises abundances of $\mathrm{C}_{3}$ species and diacetylene, and lowers abundance of benzene. This first result indicates that heterogenous processes may affect significantly the photochemistry in Titan's atmosphere and should not be neglected in the studies of Titan's stratospheric composition.

\section{Acknowledgments}

This work was performed while S. Lebonnois held a National Research Council Research Associateship Award at NASA Ames Research Center. E.L.O. Bakes thanks NASA's Exobiology Program for her support in this research. The authors thank Emmanuel Lellouch and JeanLoup Bertaux for their suggestions to improve this paper.

\section{References}

Arthur, N.L., 1986. Methyl radical absorption cross section at $216.4 \mathrm{~nm}$ and rate constant for methyl radical recombination. J. Chem. Soc. Faraday Trans. 2 82, 331-336.

Bakes, E.L.O., Lebonnois, S., Bauschlicher Jr., C.W., McKay, C.P., 2003. The role of submicrometer aerosols and macromolecules in $\mathrm{H}_{2}$ formation in the Titan haze. Icarus 161, 468-473.

Banaszkiewicz, M., Lara, L.M., Rodrigo, R., López-Moreno, J.J., MolinaCuberos, G.J., 2000. A coupled model of Titan's atmosphere and ionosphere. Icarus 147, 386-404.

Bertaux, J.-L., Kockarts, G., 1983. Distribution of molecular hydrogen in the atmosphere of Titan. J. Geophys. Res. A 88, 8716-8720.

Courtin, R., Gautier, D., McKay, C.P., 1995. Titan's thermal emission spectrum: reanalysis of the Voyager infrared measurements. Icarus 114, 144-162.

Coustenis, A., Bézard, B., Gautier, D., 1989. Titan's atmosphere from Voyager infrared observations. I. The gas composition of Titan's equatorial region. Icarus $80,54-76$.

Dobrijevic, M., Parisot, J.P., 1998. Effects of chemical kinetics uncertainties on hydrocarbon production in the stratosphere of Neptune. Planet. Space Sci. 46 (5), 491-505.

Galand, M., Lilensten, J., Toublanc, D., Maurice, S., 1999. The ionosphere of Titan: ideal diurnal and nocturnal cases. Icarus 140, 92-105.

Huebner, W.F., Keady, J.J., Lyon, S.P., 1992. Solar photo rates for planetary atmospheres and atmospheric pollutants. Astrophys. Space Sci. 195, 1-302.

Hunten, D.M., 1973. The escape of $\mathrm{H}_{2}$ from Titan. J. Atmos. Sci. 30, $726-732$

Lara, L.M., Lellouch, E., López-Moreno, J.J., Rodrigo, R., 1996. Vertical distribution of Titan's atmospheric neutral constituents. J. Geophys. Res. E 101, 23261-23283. 
Lebonnois, S., Toublanc, D., 1999. Actinic fluxes in Titan's atmosphere, from one to three dimensions: application to high-altitude composition. J. Geophys. Res. 104, 22025-22034.

Lebonnois, S., Toublanc, D., Hourdin, F., Rannou, P., 2001. Seasonal variations in Titan's atmospheric composition. Icarus 152, 384-406.

Lebonnois, S., Bakes, E.L.O., McKay, C.P., 2002.Transition from gaseous compounds to aerosols in Titan's atmosphere. Icarus 159, 505-517.

McKay, C.P., 1996. Elemental composition, solubility, and optical properties of Titan's organic haze. Planet. Space Sci. 44 (8), 741-747.

Mordaunt, D.H., Lambert, I.R., Morley, G.P., Ashfold, M.N.R., Dixon, R.N., Western, C.M., 1993. Primary product channels in the photodissociation of methane at $121.6 \mathrm{~nm}$. J. Chem. Phys. 98 (3), 2054-2065.

Rannou, P., Hourdin, F., McKay, C.P., 2002. A wind origin for Titan's haze structure. Nature 418, 853-856.

Samuelson, R.E., Nath, N.R., Borysow, A., 1997. Gaseous abundances and methane supersaturation in Titan's troposphere. Planet. Space Sci. 45 959-980.

Smith, G.R., Strobel, D.F., Broadfoot, A.L., Sandel, B.R., Shemansky, D.E., Holberg, J.B., 1982. Titan's upper atmosphere: composition and temperature from the EUV solar occultation results. J. Geophys. Res. 87, 1351-1359.

Smith, N.S., Raulin, F., 1999. Modeling of methane photolysis in the reducing atmospheres of the outer solar system. J. Geophys. Res. 104, 1873-1876.

Smyth, W.H., 1981. Titan's hydrogen torus. Astrophys. J. 246, 344-353.

Strobel, D.F., Summers, M.E., Zhu, X., 1992. Titan's upper atmosphere: structure and ultraviolet emissions. Icarus 100, 512-526.

Toublanc, D., Parisot, J.P., Brillet, J., Gautier, D., Raulin, F., McKay, C.P., 1995. Photochemical modeling of Titan's atmosphere. Icarus 113, 2-26.

Vervack Jr., R.J., 1997. Titan's Upper Atmospheric Structure Derived from Voyager Ultraviolet Spectrometer Observations, Ph.D. thesis. Univ. of Arizona.

Vervack Jr., R.J., Sandel, B.R., Strobel, D.F., 1999. First results from a reanalysis of the Voyager I ultraviolet spectrometer solar occultations by Titan. Icarus, submitted for publication.

Yung, Y.L., Allen, M., Pinto, J.P., 1984. Photochemistry of the atmosphere of Titan: comparison between model and observations. Astrophys. J. Suppl. 55, 465-506. 